\title{
Facilitate Signing with the Family Doctor: A Study of the Practice in Shanghai, China
}

\author{
Huimin Dai' \\ Lan Tang' \\ Zhaoxin Wang ${ }^{2}$ \\ Xiaoming Sun ${ }^{3}$ \\ Fang Zhang' \\ Min Zhu' \\ Qian Huang' \\ Bing $\mathrm{Hu}^{\prime}$ \\ Linqiang Wang' \\ Xianqin $\mathrm{Fu}^{\prime}$ \\ Li Luo ${ }^{3}$ \\ Jianwei $\mathrm{Shi}^{2,4}$ \\ 'Shanghai Pudong Weifang Community \\ Health Center, Shanghai, 200I20, People's \\ Republic of China; '2School of Public Health, \\ Shanghai Jiaotong University School of \\ Medicine, Shanghai, 200025, People's \\ Republic of China; ${ }^{3}$ School of Public Health, \\ Fu Dan University School of Medicine, \\ Shanghai, 200433, People's Republic of \\ China; ${ }^{4}$ Department of General Practice, \\ Yangpu Hospital, Tongji University School \\ of Medicine, Shanghai, 200090, People's \\ Republic of China
}

Correspondence: Lan Tang; Jianwei Shi Email tang199@aliyun.com;

shijianwei_amy@I26.com
Background: In the time since primary care was implemented in China in 2009, programs of promoting residents signing with family doctor services have been key. However, there has been a lack of effective evaluation of its implementation.

Methods: We used mixed methods for evaluating existing measures of facilitating signing with family doctors in Shanghai. Based on the Donabedian model, qualitative informant interviews were conducted to obtain experts' evaluations in aspects of team construction (structure) and innovative solutions for promoting and supervising signings (process). Quantitative data were used to analyse the utilization situation (outcome) from "Shanghai Family Doctor Signing Data Platform”.

Results: Measures of signing with family doctors in Shanghai have functioned well, but there is still a lack of sufficient family doctors and specialists, including paediatricians and gynaecologists. Although proportions of the key population (average $=62.59 \%$ ) and the elderly population $(>65$ years) (average $=78.10 \%$ ) who had signed with family doctors were relatively high, the proportion of the permanent resident population (average $=29.36 \%$ ) who had signed with family doctors was low from 2017 to 2020 in Shanghai. The proportions of residents seeking medical advice in signed community health centres in outskirts (71.08\%) were higher than those in suburbs (63.51\%) and urban areas (53.49\%), whereas the proportion of those seeking medical advice from recommended multiple medical institutions were similarly low in urban areas, outskirts and suburbs.

Conclusion: The practice of facilitate signing with family doctors in Shanghai has increased. However, we showed that numbers of family doctors were relatively low, and there remains a need for more experienced gynaecology and paediatrics professionals, compared with Western countries. Additionally, efforts should be made to increase proportions of residents who utilize the program, especially in urban areas, and seek medical services in contracted group hospitals and community health centres.

Keywords: primary care, family doctor service, evaluation, practice

\section{Introduction}

Primary medical service systems centred on a family doctor system have been implemented in more than 50 developed countries and regions around the world, and some achievements have been made. The UK, which attaches great importance to primary health care, has one of the lowest costs of primary health care. ${ }^{1}$ For instance, in the UK, $90 \%$ of patients receive their initial diagnoses in the GP clinic, and $80 \%$ of chronic diseases are solved in the community health centres, with the use of approximately only $30 \%$ of the NHS budget. ${ }^{1}$ The number of family doctors in the United States accounts for approximately $60 \%$ of clinicians. ${ }^{1}$ Under normal circumstances, $80-90 \%$ of health problems of community residents can be properly solved in family doctors' clinics, 
and only $6.3 \%$ of patients need to be referred by family doctors to specialists for further treatment. In Australia, more than $80 \%$ of residents seek family doctor services each year. ${ }^{2-4}$ Commonly, family doctors play the role of "health gatekeepers", and patients rely heavily on them.

However, the development of primary health care in China was relatively late. From the early days of the founding of the People's Republic of China to the days before the reform and opening up (1950-1979), "barefoot doctors" were vigorously promoted, and these doctors played a role similar to that of family doctors in Western countries. However, after the reform and opening, as well as due to the lack of national health funds, the government began to reduce the financial budget for hospitals and encouraged hospitals to operate independently which greatly increased the competition between secondary or tertiary hospitals and primary care centres, and gradually weakened the ability of primary care centres. ${ }^{2}$ It was not until China's new round of healthcare reform in 2009 that the Chinese government placed more emphases on improving primary care services. ${ }^{3-6}$ A series of policy documents (Figure 1) was issued to promote GPs as

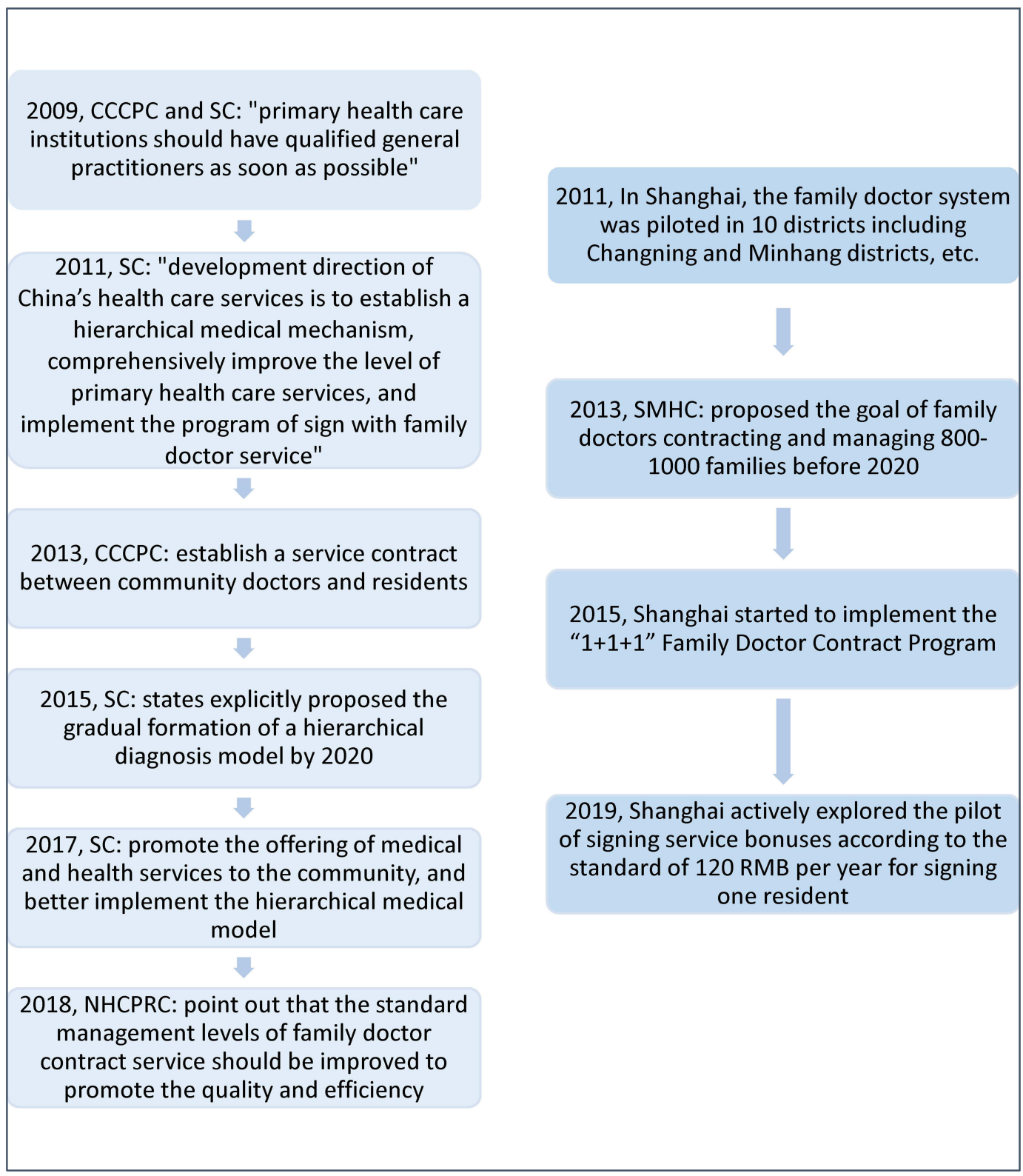

Figure I Policies of family doctor contract services in China between 2009 and 2019.

Abbreviations: CCCPC, Central Committee of the Communist Party of China; SC, State Council; NHCPRC: National Health Commission of the People's Republic of China; SMHC, Shanghai Municipal Health Commission. 
"health gatekeepers". However, the GPs in China only initially provided the service of treating patients in health institutions, which was not fully realized as being the function of GPs in the developed countries. In 2011, the State Council noted the need to comprehensively improve the level of primary healthcare services and to implement the program of signing with a family doctor, in order to improve the function of GPs; additionally, these GPs are needed to provide health services in both the health institutions and in the home. ${ }^{7}$ These GPs were specifically known as family doctors in China. As a result, in 2013, the Central Committee of the Communist Party of China proposed the program of health service contracts between family doctors and residents. ${ }^{7,8}$ In 2018, "Guiding Opinions on Regulating the Management of Family Doctor Contract Services" pointed out that the standard management levels of family doctor contract services should be improved to promote their quality and efficiency. ${ }^{9}$ Among all of the cities in China, Shanghai has prioritized the introduction and development of community healthcare services. A pilot family doctor system was launched in Shanghai in 2011, and information on their accumulated experience has been discussed. ${ }^{10,11}$ The residents were encouraged to use family doctor services, such as priority referral appointments, convenient medications, targeted health management, medical insurance management and other supporting services, in order to gradually establish a hierarchical medical system and to fully realize the gatekeeper role of family doctors. ${ }^{12-14}$

Due to the lack of qualitative systematic summaries and quantitative evaluations in the existing studies, this study aimed to summarize the experience of the promotion of the scheme of signings with family doctors in Shanghai and to evaluate its effectiveness. When regarding the promotion of family doctor services in China, Shanghai is far ahead of other cities in China; however, the circumstances commonly involve the idea that patients can freely choose the type of primary care and specialist without strict restrictions. Therefore, this study has an important reference value for the promotion of signing with family doctors and the reform of primary healthcare services in other regions of China and in other developing countries.

\section{Method}

\section{Analytic Framework}

This study used both qualitative and quantitative methods to evaluate family physician contract measures. The Donabedian model ${ }^{15}$ provides a framework to evaluate the characteristics of the Family Doctor Contract Service Program schemes in three categories: structure, process and outcomes. Based on Donabedian's framework, the qualitative component of the study systematically summarized current common Family Doctor Contract Service Program schemes by interviewing 12 directors of community health services who were responsible for these programs, when regarding the structure and process of the programs. Questions designed for experts were related to the design of the program (structure), its implementation (process). The main discussion questions for the evaluation were as follows: 1) biographical information and experience (eg, age, gender, professional title); 2) awareness of the experiences of the family physician contract policy; 3) description of schemes of sign with a family doctor, including its design, execution/implementation, and effectiveness in China. The interview questions were open-ended. Furthermore, from the quantitative perspective, and to support the evaluation (particularly, the "outcome" section of the framework), we assessed the utilization rate of the scheme of signing with the family doctor from 2015 in the leading community healthcare centre in Shanghai.

\section{Data Source \\ Qualitative Data}

To evaluate the current common scheme of signing with a family doctor, we chose 15 experts who were directors of community health centres, officials in the Health Commission who were responsible for elementary health affairs and related scholars in Shanghai. They were given a detailed introduction of the significance, purpose, methods and content of this study. In-depth face-to-face interviews were conducted from May 6, 2020, to July 1, 2020. To obtain detailed and reliable data, each interview lasted approximately one hour and was audio recorded. The audio recordings were returned to the respondents for confirmation after each interview. We recorded the respondents' gender, age, title, education, and occupation.

\section{Quantitative Data}

In 2015 , to monitor the proportion of the population signing contracts in each community healthcare centre in Shanghai, the Family Doctor Signing Data Platform was established. The platform performs real-time monitoring of signing data, including the proportions of permanent residents, key populations among permanent residents (elderly individuals up to 60 years old; pregnant women; children; disabled individuals; family members who 
require special family planning; and patients with hypertension, diabetes, tuberculosis, and serious mental disorders ${ }^{16}$ ) and the elderly population up to 65 years old among permanent residents who have signed contracts. In addition, the platform tracks the proportions of residents seeking medical advice from multiple given types of medical institutions, which were measured as the sum of the number of consultations at community health centres, regional secondary hospitals and tertiary hospitals contracted with residents, divided by the total number of consultations at community health centres contracted with residents. Finally, the platform records the proportion of community health service centre consultations, measured as the number of consultations at community health centres divided by the total number of consultations of contracted residents. We collected data starting in 2017, the year in which the online system was launched and the programme began its two-year implementation period. The uploaded data provided a comprehensive status of the programme in Shanghai.

\section{Data Analysis}

Regarding the qualitative portion of the study, two trained researchers analysed the qualitative data using NVivo 10 to sort the interview answers. The Donabedian model was used as an a priori organizational framework. Using a hierarchical coding structure, the researchers deductively identified all themes and then coded and analysed the transcripts that were relevant. The transcripts were double coded (ie, coded independently by the two researchers), and the results were compared and discussed until consensus was reached.

A descriptive analysis was conducted for the utilization situation, including the proportion of permanent residents in Shanghai who signed contracts, the proportion of people over 65-years-old who signed contracts, the rate of first diagnosis in community healthcare centres and the rate of diagnosis in recommended multiple medical institutions. The descriptive statistics included the number, mean, standard deviation, and proportion of these variables from 2017 to 2020 .

\section{Results}

\section{Qualitative Evaluation of Schemes of} Signing with Family Doctors in Shanghai Evaluation of Contract Service Team Construction

At present, the signing of contracts by residents with family doctors in Shanghai is assisted by the residents' committees (in China, the residents' committee plays an important role in assisting the sub-district offices in handling social and public affairs). A team of family doctors (one GP + one assistant $+\mathrm{N}$ (public health doctors, residents committee cadres, volunteers, etc.)) is formed, with a team leader at the core. The GP is responsible for the organization, leadership and quality control of the team's work, as well as for performing specific diagnoses and treatment services, including outpatient diagnoses and treatments and medicine management services for contracted patients. The assistant assists the GP in completing the contract signing, arranging appointments, establishing and updating health records, following up on chronic diseases, providing health information, performing physical examinations of elderly patients and screening for chronic diseases related to public health. Public health doctors are responsible for public health-related service consultation, chronic disease management and follow-up. The cadres and volunteers of the neighbourhood committee assist the GP in establishing connections and contact with residents.

Specifically, in terms of medical service provisions, to better attract patients, community health centres generally set up a family doctor service team with a complete set of professionals. Specifically, for a certain kind of disease, the team usually cooperates with a counterpart specialist from a tertiary hospital in the region and establishes a full specialist team. For example, for diabetes care, when considering type 2 diabetes as the starting point, a community in Pudong New Area cooperated with a tertiary hospital in its area to set up a "Renji - Weifang" (Renji is a tertiary hospital and Weifang is a community healthcare institution) diabetes disease facility in the community, which was composed of 1 specialist, 4 GPs and 1 diabetes specialist nurse. Usually, half a day each week was dedicated to outpatients, focusing on appointments for patients with nonideal glycosylated haemoglobin (hbAlc) levels that have previously agreed to the " $1+1+1$ " contract, with 15-20 patients being seen each half day. The nurses completed routine physical examinations, such as height, weight, waist circumference, and blood pressure. At the same time, we provided a rotation service between Renji Hospital and the "Renji - Wei fang" diabetes disease facility according to the agreed-upon grading diagnosis treatment standards and the actual situations of patients.

Currently, among the 246 community health centres in Shanghai, 175 centres can offer paediatric diagnoses and treatment services. However, all of the centres are already in service to provide outpatient appointments, preventions 
related to health care between the ages of $0-6$ years, health records and other common services for infants. Interestingly, many GPs and their teams have expanded to sign up entire families after originally signing up only children.

When regarding the composition of the contract service team in Shanghai, as required by the government, each team should equip at least one family doctor, one nurse, one public health physician (can be part-time) and one rehabilitation therapist, with the family doctors representing the core individual in the team. This condition was well met by all of the community health centres in Shanghai. However, the number of family doctors was not sufficient compared to their considerable work load, especially regarding door-to-door services. When considering this scenario, the Shanghai government has implemented various measures, including service bonuses of $120 \mathrm{RMB}$ for the team if they are able to successfully sign one resident. Another problem is that, in certain community health centres, the family team does not include gynaecology or paediatric professionals, and some of these individuals are unable to diagnose via chest radiographs or electrocardiograms.

\section{Evaluation of Various Innovative Solutions to} Promote and Supervise the Schemes of Signings with Family Doctors

Regular Door-to-Door and Community Canvassing to Promote Contract Signing

In terms of publicity, community health centres usually organize family doctors, assistants, neighbourhood community cadres and public health personnel to participate in publicity and the provision of services for residents in the neighbourhood, communities and outpatient departments. Family doctors perform consultations with individuals from the entire neighbourhood and publicize signings among residents. Assistants conduct telephone follow-up and ensure that everyone has been appropriately informed according to the household registration. While the canvassing of the area continues, family doctor groups are arranged to give informative speeches in the community related to the family doctor policy. Relevant leaflets are distributed in corridors and public spaces, among other settings, where posters with information and pictures of family doctors are also placed. These efforts are taken to further strengthen public awareness and support.

\section{Information Support}

From the time of 2018, the method of signing has changed from the original paper-based registration form to online contract signing. Family doctors can provide face-to-face contract signing for residents using mobile phones. Residents can also query family doctors from community health centres through the use of the health platform of each district (such as the Pudong Health Information Platform). On the platform, they can select and apply for family doctors according to their needs.

Many community health centres have developed computer systems to assist in the identification of medical insurance card information and the establishment of a general outpatient-oriented triage system. With the help of medical insurance card information recognition, patients can be divided into two categories: signed and not signed. Before registration, patients who have signed must go to the triage nurse table The triage nurse informs the family doctor of the clinic and guides the patient to the corresponding family doctor's clinic. Doctors can lead contracted patients through to the correct room by using the computer and the intercoms placed in waiting areas to announce they are ready to see them; this is done to promote continuous and consistent services to patients who have signed contracts. This approach has solved problems such as the presence of patients who have signed contracts but not booked appointments to meet their doctors and who see the appointment as a mere formality.

In addition, the health cloud platform and the family doctor management application (app) have been popularized in Shanghai. Family doctors can query the medical treatment situations of community residents in the whole city, including their hospital information, diagnoses, test results, examinations, medications and medical insurance expenses. In addition, they can follow the health status of residents in a timely manner. By telephone or chat, they can immediately follow up about the disease and provide community health guidance, and they can inform residents that they can provide medicines from higher-level hospitals through extended prescriptions to reduce unnecessary visits to higher-level hospitals.

\section{Quality Control System for the Scheme}

In the process of signing a contract, most communities pay attention to the service quality assessment. The first part of the assessment involves the identification of the number of patients who have signed a contract with 
a doctor and the demographics of that group, which are used as the basis for workload statistics and incentive allocation (mentioned by all 12 interviewed communities). The second is a post-signing weekly/monthly/ quarterly forum among the GP signing teams to synchronize and discuss the current contract signing progress, signing skills, and problems encountered in the process of signing; 50-100 people are randomly selected for telephone follow-ups every month to understand the satisfaction rate and listen to the feedback. In addition, a third party is entrusted to make a follow-up call every six months to understand the awareness and satisfaction of the contracted party with the family doctor service, communicate in a timely manner and provide feedback, and track and verify the problems that are found. Third, the incentive payment for signing is gradually being linked to the quality of service. The contract service fee is a system that has been implemented since 2019; signing up a resident with a GP team can lead to a bonus payment for the signing team member, and the initial payment is measured only based on the number of residents contracted. However, an increasing number of community health centres are proposing establishing a team distribution system that takes into account both the signing process and the results into the assessment, which would ensure a fair payment of service fees and better motivate team members.

\section{Quantitative Evaluation of Schemes on Signings with Family Doctors in Shanghai}

As seen in Table 1, at the end of 2020, Shanghai had $22,467,089$ permanent residents $(6,621,629$ [29.47\%] living in urban areas, $10,817,532$ [48.15\%] living in the outskirts and 5,027,928 [22.38\%] living in the suburbs) and 5.839 million key populations. Among these populations, the number of 65 -year-old individuals increased year by year, accounting for $15.78 \%(3,544,991 / 22,467,089)$ of the total population in 2020 . However, although the number of GPs increased from 2019 to 2020 , there were only 3.62 GPs $(8128 / 22,399,358)$ for every 10,000 residents in 2019 and 3.91 GPs $(8782 / 22,467,089)$ for every 10,000 residents in 2020 .

As shown in Table 2, in general, the signing rate of permanent residents and key populations increased from 2017 to 2020 . The average proportion of key populations and seniors aged 65 and above in Shanghai who signed contracts was significantly higher in the outskirts (key population: $71.08 \%$; aged $>65$ years: $93.14 \%$ ) than in urban areas (key population: $53.49 \%$; aged $>65$ years: $61.00 \%$ ) or the suburbs (key population: 62.59\%; aged $>65$ years: $78.10 \%$ ). In addition, we found that in some districts in the outskirts (the districts of Minhang, Jiading and Baoshan), the proportion of seniors aged 65 and above who signed contracts was already $100 \%$ in 2020 .

When comparing the actual behaviour of residents seeking medical advice, it was found that the overall average proportions of consultations at multiple medical institutions and contracted community health centres were $71.58 \%$ and $48.61 \%$, respectively. The proportions of residents seeking medical advice at multiple medical institutions were similar in urban areas, the outskirts and the suburbs. However, the proportion of residents seeking medical advice in contracted community health centres in the outskirts $(71.08 \%)$ was higher than those in the suburbs $(63.51 \%)$ and urban areas (53.49\%) (Table 3$)$.

\section{Discussion}

As shown in this study, Shanghai has prioritized the introduction and development of promoting the schemes of signing with the family doctor. However, although the team met the basic requirements of the government, in the study, we showed that there was a considerable shortage of family doctors, which may largely influence the efficiency of the signing work, due to the fact that family doctors in China not only exhibit responsibilities of providing health services, but also practice public health duties, including disease screening, vaccination and health status follow-ups, among other services. ${ }^{17}$ Actually, when regarding Shanghai GPs in 2020, there were 3.91 GPs for every 10,000 residents in Shanghai, whereas there were 810 GPs for every 10,000 residents in developed countries. $^{18,19}$ This considerable shortage, to a great extent, makes the contract services of family doctors difficult to implement. In addition, compared with western countries, in terms of salary levels, the salary of family doctors is much higher than that of other vocations, whereas the income level of family doctors in China is relatively low. For instance, the average annual income of family doctors in the UK is 2.5 times the average in China, while that in the US is 2-7 times that in China. ${ }^{20,21}$

In terms of the multiple roles of GP teams, contracted family doctor teams in Shanghai are also constantly improving. In the past, some community health centres with only GPs and nurses have developed multiple-member teams with GPs, nurses, and assistants, similar to health follow- 


\begin{tabular}{|c|c|c|c|c|c|c|c|c|c|c|c|c|c|c|c|c|c|c|c|c|c|}
\hline \multirow{4}{*}{ 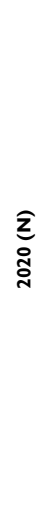 } & ż̀ & 요 & $\tilde{\tilde{n}}$ & 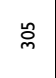 & $\hat{q}$ & $\stackrel{\circ}{m}$ & ळ్ & $\bar{\ddagger}$ & 总 & $\stackrel{\underline{m}}{\underline{\underline{\Omega}}}$ & 8 & $\frac{\sigma}{\sigma}$ & 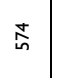 & 高 & $\bar{\sim}$ & $\widetilde{q}$ & స్ ి & 命 & $\stackrel{\circ}{m}$ & $\stackrel{\mathscr{\infty}}{\stackrel{\varrho}{\varrho}}$ & 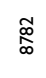 \\
\hline & 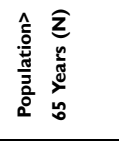 & 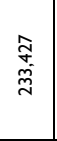 & $\begin{array}{l}\text { 孛 } \\
\stackrel{\sim}{\sim}\end{array}$ & 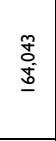 & 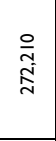 & 旁 & 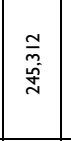 & $\begin{array}{l}\text { 产 } \\
\text { 㟧 }\end{array}$ & 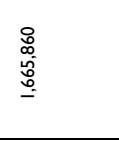 & 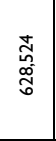 & 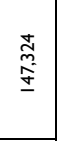 & 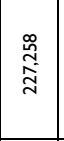 & $\begin{array}{l}\frac{d}{\Delta} \\
\frac{\Delta}{\sim} \\
\frac{\pi}{N}\end{array}$ & 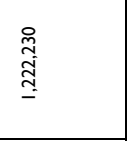 & 志 & $\begin{array}{l}\stackrel{\hat{a}}{a} \\
\stackrel{a}{=}\end{array}$ & 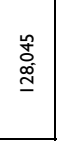 & 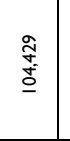 & 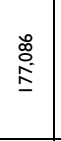 & 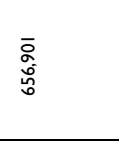 & 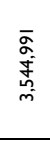 \\
\hline & 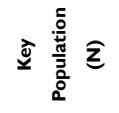 & 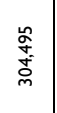 & 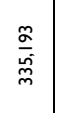 & 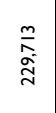 & 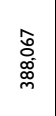 & 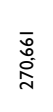 & 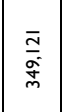 & $\begin{array}{l}\frac{\pi}{\bar{\sigma}} \\
\frac{\sigma}{\sigma} \\
\frac{\sigma}{7}\end{array}$ & 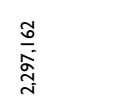 & 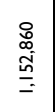 & 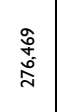 & 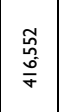 & 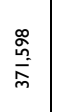 & 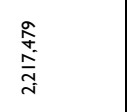 & $\begin{array}{l}\stackrel{0}{0} \\
\stackrel{\circ}{\sim} \\
\stackrel{\sim}{\sim}\end{array}$ & $\begin{array}{l}\stackrel{\widetilde{o}}{\circ} \\
\stackrel{\sim}{\sim}\end{array}$ & 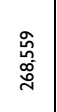 & 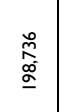 & 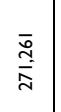 & 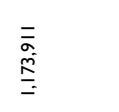 & 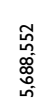 \\
\hline & 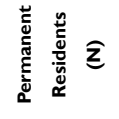 & 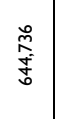 & 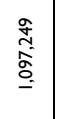 & 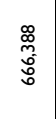 & $\frac{\stackrel{\circ}{=}}{\bar{\alpha}}$ & 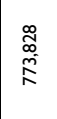 & $\mid$ & 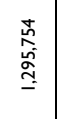 & 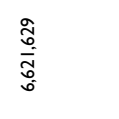 & 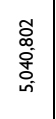 & 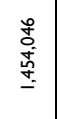 & 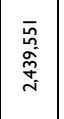 & $\begin{array}{l}\underset{m}{\underline{m}} \\
\substack{\tilde{\omega} \\
\underline{m}} \\
\underline{-}\end{array}$ & 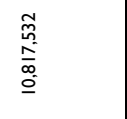 & 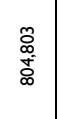 & 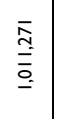 & 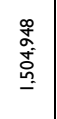 & 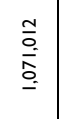 & 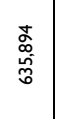 & 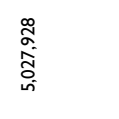 & 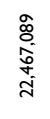 \\
\hline \multirow{4}{*}{$\begin{array}{l}\bar{z} \\
\text { òे }\end{array}$} & $\bar{z}_{0}$ & $\stackrel{\circ}{\sim}$ & $\stackrel{\widehat{\infty}}{\sim}$ & $\frac{m}{N}$ & 总 & $\bar{\lambda}$ & 品 & $\stackrel{P}{\circ}$ & ఫ્ત & $\stackrel{\circ}{\stackrel{\circ}{0}}$ & 总 & $\frac{m}{0}$ & $\frac{d}{\frac{\pi}{4}}$ & o & $\stackrel{\sim}{ \pm}$ & $\stackrel{\sim}{\sim}$ & $\tilde{m}$ & $\widehat{\text { 心 }}$ & $\stackrel{\infty}{\sim}$ & 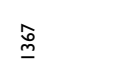 & $\stackrel{\infty}{\underset{\infty}{\infty}}$ \\
\hline & 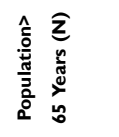 & 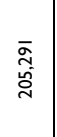 & 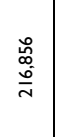 & $\begin{array}{l}\frac{0}{n} \\
\underline{\underline{\underline{x}}}\end{array}$ & $\begin{array}{l}\overline{\mathrm{o}} \\
\mathrm{o} \\
\mathrm{o} \\
\mathrm{\sigma}\end{array}$ & 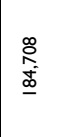 & 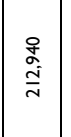 & 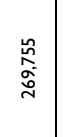 & 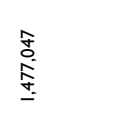 & 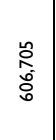 & 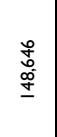 & 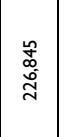 & 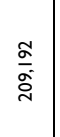 & 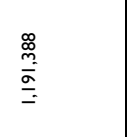 & $\begin{array}{l}\stackrel{\hat{0}}{0} \\
\cong\end{array}$ & $\stackrel{\substack{\stackrel{\infty}{E} \\
=}}{=}$ & 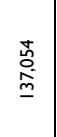 & 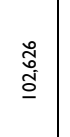 & 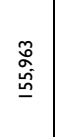 & 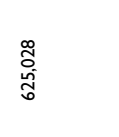 & 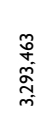 \\
\hline & 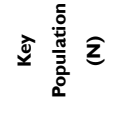 & 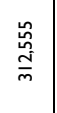 & $\frac{8}{8}$ & $\begin{array}{l}\hat{o} \\
\stackrel{8}{d} \\
\stackrel{d}{d}\end{array}$ & 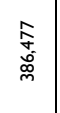 & 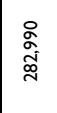 & 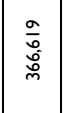 & 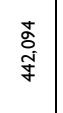 & 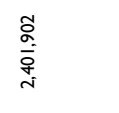 & 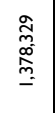 & 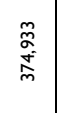 & 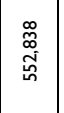 & 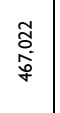 & $\begin{array}{l}\underset{N}{N} \\
\underset{N}{N}\end{array}$ & 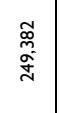 & 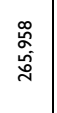 & 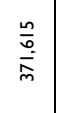 & 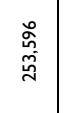 & 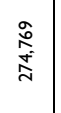 & 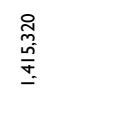 & 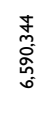 \\
\hline & 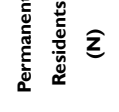 & 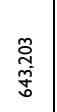 & $\begin{array}{l}\text { 总 } \\
\text { 惫 } \\
\stackrel{0}{-}\end{array}$ & 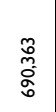 & 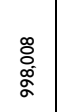 & 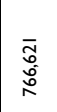 & $\mid$ & 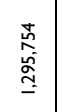 & 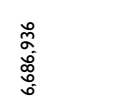 & 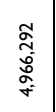 & 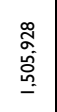 & 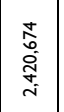 & 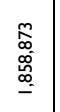 & 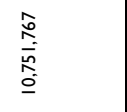 & $\begin{array}{c}\frac{\sigma}{\sigma} \\
\frac{\sigma}{\sigma} \\
\frac{\sigma}{\infty}\end{array}$ & 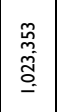 & 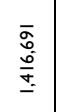 & 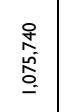 & 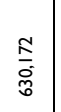 & 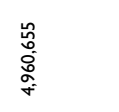 & 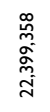 \\
\hline \multirow{4}{*}{$\begin{array}{l}\Sigma_{2} \\
\frac{\infty}{i}\end{array}$} & ईิ & - & - & - & - & - & - & - & - & - & - & - & - & - & - & - & - & - & - & - & - \\
\hline & 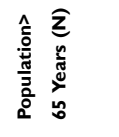 & $\begin{array}{l}\stackrel{8}{\circ} \\
\stackrel{0}{0} \\
\stackrel{0}{0}\end{array}$ & 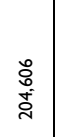 & 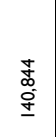 & \begin{tabular}{|l|}
\multirow{\pi}{*}{} \\
\multirow{\sim}{*}{} \\
\end{tabular} & 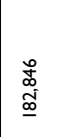 & \begin{tabular}{|l|}
$\mid \begin{array}{c}\sigma \\
\alpha \\
\alpha \\
\sigma\end{array}$ \\
\end{tabular} & 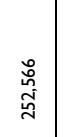 & 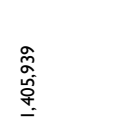 & 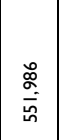 & 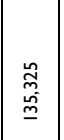 & $\left|\begin{array}{c}0 \\
0 \\
\tilde{~} \\
\tilde{~}\end{array}\right|$ & $\begin{array}{l}\frac{\stackrel{\alpha}{o}}{\sigma} \\
\underline{\underline{\omega}}\end{array}$ & 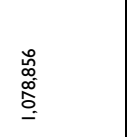 & $\mid \begin{array}{l}\frac{t}{\hat{S}} \\
\underline{\underline{S}}\end{array}$ & 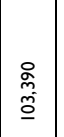 & 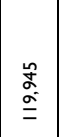 & $\frac{o}{a+\frac{9}{\sigma}}$ & 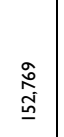 & 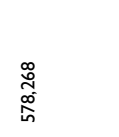 & \begin{tabular}{|c|c}
0 \\
0 \\
0 \\
0 \\
0 \\
$\tilde{m}$
\end{tabular} \\
\hline & 六畜 & 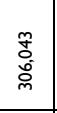 & 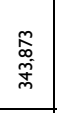 & $\begin{array}{l}\stackrel{m}{ } \\
\stackrel{\sim}{\pi} \\
\end{array}$ & 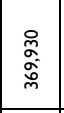 & 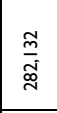 & $\mid \begin{array}{c}\tilde{m} \\
\tilde{f} \\
\tilde{j} \\
\end{array}$ & $\begin{array}{l}\tilde{\widetilde{G}} \\
\underline{\sigma} \\
\underline{\sigma} \\
\end{array}$ & 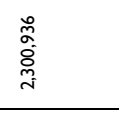 & 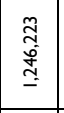 & 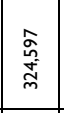 & $\mid$\begin{tabular}{c|}
$\overline{0}$ \\
$\infty$ \\
$\infty$ \\
$\sigma$ \\
$\sigma$
\end{tabular} & 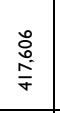 & 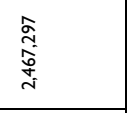 & \begin{tabular}{|c|} 
\\
$\stackrel{\infty}{0}$ \\
$\tilde{\tilde{N}}$ \\
\end{tabular} & 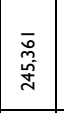 & \begin{tabular}{|l|}
\multirow{0}{*}{} \\
d्ञ \\
\end{tabular} & 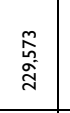 & 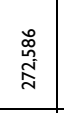 & 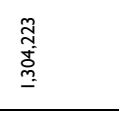 & 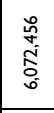 \\
\hline & 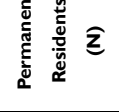 & 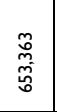 & 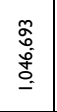 & $\begin{array}{l}\frac{2}{3} \\
\frac{1}{0} \\
\overline{0}\end{array}$ & 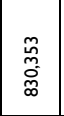 & 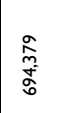 & 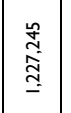 & 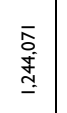 & 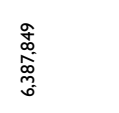 & 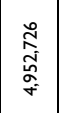 & 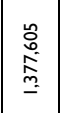 & 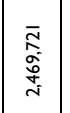 & 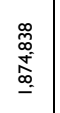 & 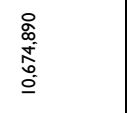 & $\frac{\sigma}{\stackrel{\sigma}{R}}$ & 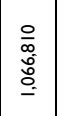 & 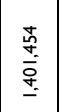 & 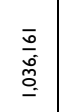 & 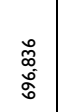 & $\begin{array}{l}\frac{w}{b} \\
\infty \\
o \\
\sigma \\
\sigma \\
\sigma\end{array}$ & 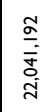 \\
\hline \multirow{4}{*}{$\begin{array}{l}\hat{z} \\
\hat{\bar{a}}\end{array}$} & $\tilde{v} \hat{z}$ & - & - & - & - & - & - & - & - & - & - & - & - & - & - & - & - & - & - & - & - \\
\hline & 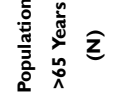 & - & - & - & - & - & - & - & - & - & - & - & - & - & - & - & - & - & - & - & - \\
\hline & 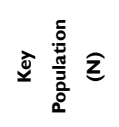 & - & - & - & 1- & - & - & - & - & - & - & - & - & - & - & - & - & - & - & - & - \\
\hline & 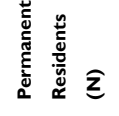 & $\begin{array}{l}0 \\
\substack{0 \\
\text { of } \\
i n}\end{array}$ & 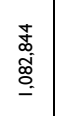 & 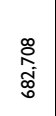 & 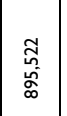 & $\frac{\mathfrak{z}}{\mathfrak{z}}$ & 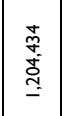 & 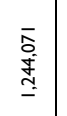 & 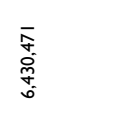 & 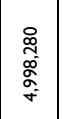 & 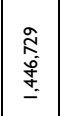 & 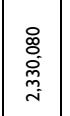 & 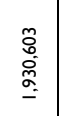 & 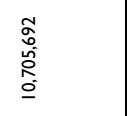 & 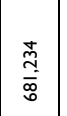 & 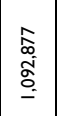 & 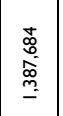 & 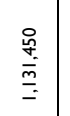 & 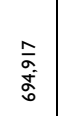 & 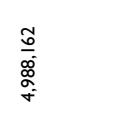 & 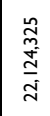 \\
\hline \multicolumn{2}{|l|}{ 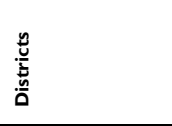 } & 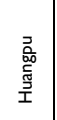 & 言 & 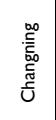 & 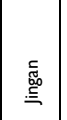 & 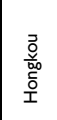 & 总 & 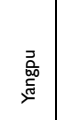 & 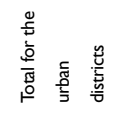 & \begin{tabular}{|l|}
0 \\
$\frac{5}{2}$ \\
$\frac{0}{2}$ \\
2
\end{tabular} & 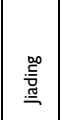 & 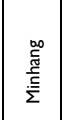 & 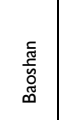 & 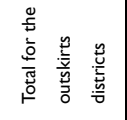 & 亳 & 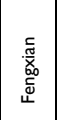 & 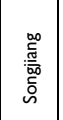 & 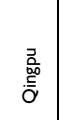 & 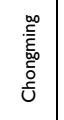 & 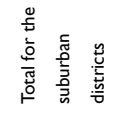 & 殷 \\
\hline
\end{tabular}


Table 2 The Proportions of Different Populations Who Signed a Contract in Each District in Shanghai (2017-2020)

\begin{tabular}{|c|c|c|c|c|c|c|c|c|c|c|c|c|c|c|c|c|}
\hline & \multirow[t]{2}{*}{ Districts } & \multicolumn{5}{|c|}{$\begin{array}{l}\text { Signing Proportion Among Permanent } \\
\text { Residents (\%) }\end{array}$} & \multicolumn{5}{|c|}{$\begin{array}{c}\text { Signing Proportion Among the Key } \\
\text { Population (\%) }\end{array}$} & \multicolumn{5}{|c|}{$\begin{array}{c}\text { Signing Proportion Among People }>65 \\
\text { Years (\%) }\end{array}$} \\
\hline & & 2017 & 2018 & 2019 & 2020 & Average & 2017 & 2018 & 2019 & 2020 & Average & 2017 & 2018 & 2019 & 2020 & Average \\
\hline \multirow[t]{8}{*}{ Urban } & Huangpu & 17.01 & 30.11 & 32.98 & 32.34 & 28.11 & 1 & 35.66 & 38.05 & 43.61 & 39.11 & 1 & 40.22 & 43.53 & 46.17 & 44.85 \\
\hline & Xuhui & 20.95 & 30.82 & 34.19 & 34.3 & 30.07 & 1 & 56.53 & 54.79 & 68.08 & 59.80 & 1 & 66.72 & 64.88 & 72.49 & 68.69 \\
\hline & Changning & 7.53 & 27.10 & 41.17 & 46.63 & 30.61 & 1 & 28.44 & 41.77 & 70.33 & 46.85 & 1 & 34.10 & 51.94 & 72.26 & 62.10 \\
\hline & Jingan & 26.22 & 41.62 & 34.77 & 37.85 & 35.12 & 1 & 54.67 & 54.95 & 58.55 & 56.06 & 1 & 53.18 & 56.45 & 59.95 & 58.20 \\
\hline & Hongkou & 24.30 & 36.76 & 33.56 & 33.14 & 31.94 & 1 & 54.57 & 55.03 & 61.93 & 57.18 & 1 & 57.72 & 58.85 & 63.93 & 61.39 \\
\hline & Putuo & 20.16 & 33.50 & 37.55 & 36.69 & 31.98 & 1 & 57.87 & 61.74 & 72.21 & 63.94 & 1 & 67.19 & 70.12 & 75.25 & 72.69 \\
\hline & Yangpu & 24.23 & 27.63 & 30.77 & 31.58 & 28.55 & 1 & 49.23 & 47.00 & 58.34 & 51.52 & 1 & 58.46 & 55.54 & 62.66 & 59.10 \\
\hline & $\begin{array}{l}\text { Average } \\
\text { for the } \\
\text { urban } \\
\text { districts }\end{array}$ & 20.06 & 32.51 & 35.00 & 36.08 & 30.91 & & 48.14 & 50.48 & 61.86 & 53.49 & & 53.94 & 57.33 & 64.67 & 61.00 \\
\hline \multirow[t]{5}{*}{ Outskirts } & Pudong & 7.41 & 32.48 & 36.11 & 37.30 & 28.33 & 1 & 59.15 & 63.28 & 85.76 & 69.40 & 1 & 80.15 & 81.86 & 98.86 & 90.36 \\
\hline & Jiading & 14.40 & 23.18 & 31.39 & 33.48 & 25.61 & 1 & 56.09 & 52.92 & 85.97 & 64.99 & 1 & 85.33 & 83.08 & 100.00 & 91.54 \\
\hline & Minhang & 11.69 & 30.65 & 33.29 & 34.03 & 27.42 & 1 & 53.80 & 63.05 & 91.88 & 69.58 & 1 & 79.13 & 88.92 & 100.00 & 94.46 \\
\hline & Baoshan & 16.42 & 32.36 & 33.64 & 40.14 & 30.64 & 1 & 69.49 & 69.12 & 102.42 & 80.34 & 1 & 93.64 & 92.37 & 100.00 & 96.19 \\
\hline & $\begin{array}{l}\text { Average } \\
\text { for the } \\
\text { outskirts } \\
\text { districts }\end{array}$ & 12.48 & 29.67 & 33.61 & 36.24 & 28.00 & & 59.63 & 62.09 & 91.51 & 71.08 & & 84.56 & 86.56 & 99.72 & 93.14 \\
\hline \multirow[t]{7}{*}{ Suburbs } & Jinshan & 30.61 & 31.88 & 34.31 & 41.49 & 34.57 & I & 60.41 & 58.23 & 82.47 & 67.04 & I & 78.66 & 76.10 & 92.59 & 84.35 \\
\hline & Fengxian & 17.59 & 29.01 & 31.17 & 33.11 & 27.72 & 1 & 57.56 & 58.06 & 80.32 & 65.31 & 1 & 85.18 & 86.05 & 100.00 & 93.03 \\
\hline & Songjiang & 15.02 & 23.23 & 31.27 & 31.18 & 25.18 & 1 & 50.05 & 47.83 & 81.64 & 59.84 & 1 & 78.08 & 75.40 & 100.00 & 87.70 \\
\hline & Qingpu & 10.01 & 17.57 & 22.46 & 31.78 & 20.46 & 1 & 41.57 & 43.21 & 83.41 & 56.06 & I & 71.85 & 72.62 & 100.00 & 86.31 \\
\hline & Chongming & 29.26 & 35.04 & 40.25 & 42.98 & 36.88 & 1 & 65.46 & 64.97 & 77.44 & 69.29 & 1 & 80.97 & 81.51 & 88.35 & 84.93 \\
\hline & $\begin{array}{l}\text { Average } \\
\text { for the } \\
\text { suburban } \\
\text { districts }\end{array}$ & 17.97 & 26.21 & 31.29 & 34.76 & 27.56 & & 53.66 & 53.52 & 80.70 & 62.63 & & 79.02 & 78.90 & 97.09 & 87.99 \\
\hline & Total & 15.50 & 30.23 & 33.74 & 37.98 & 29.36 & I & 54.63 & 56.62 & 76.53 & 62.59 & I & 69.41 & 71.53 & 84.67 & 78.10 \\
\hline
\end{tabular}

Note: /Indicates that these data could not be obtained from the data platform.

ups in Britain, collaborating with ophthalmologists, paediatricians, gynaecologists, pharmacists, and traditional medicine doctors. However, in certain community health centres, the family team does not include gynaecology or paediatrics, and some of them are unable to diagnose with chest radiographs or electrocardiograms. Therefore, the comprehensive diagnosis and treatment ability of these centres varies. There is still a need for improvement in terms of family doctors' contracts with service providers and service content.
In Shanghai, we witnessed innovative solutions for promoting and supervising the schemes of signings with family doctors; however, as shown in the results, although the proportion of the elderly population that has signed contracts is relatively high, the proportions of the population of permanent residents who have signed contracts, the proportion of consultations at contracted community health centres and the proportion of consultations at multiple medical institutions in Shanghai are far lower than those in developed 
Table 3 The Proportions of Residents Seeking Medical Advice from Multiple Institutions and in the Contracted Community Health Centres of Each District in Shanghai (2017-2020)

\begin{tabular}{|c|c|c|c|c|c|c|c|c|c|c|c|}
\hline & \multirow[t]{2}{*}{ Districts } & \multicolumn{5}{|c|}{$\begin{array}{l}\text { Seeking Medical Advice from Multiple } \\
\text { Institutions (\%) }\end{array}$} & \multicolumn{5}{|c|}{$\begin{array}{l}\text { Seeking Medical Advice from the } \\
\text { Contracted Community Health Centres } \\
\text { (\%) }\end{array}$} \\
\hline & & 2017 & 2018 & 2019 & 2020 & Average & 2017 & 2018 & 2019 & 2020 & Average \\
\hline \multirow[t]{8}{*}{ Urban } & Huangpu & 17.01 & 30.11 & 32.98 & 32.34 & 28.11 & 1 & 35.66 & 38.05 & 43.61 & 39.11 \\
\hline & Xuhui & 20.95 & 30.82 & 34.19 & 34.30 & 30.07 & 1 & 56.53 & 54.79 & 68.08 & 59.80 \\
\hline & Changning & 7.53 & 27.10 & 41.17 & 46.63 & 30.61 & I & 28.44 & 41.77 & 70.33 & 46.85 \\
\hline & Jingan & 26.22 & 41.62 & 34.77 & 37.85 & 35.12 & 1 & 54.67 & 54.95 & 58.55 & 56.06 \\
\hline & Hongkou & 24.30 & 36.76 & 33.56 & 33.14 & 31.94 & 1 & 54.57 & 55.03 & 61.93 & 57.18 \\
\hline & Putuo & 20.16 & 33.50 & 37.55 & 36.69 & 31.98 & I & 57.87 & 61.74 & 72.21 & 63.94 \\
\hline & Yangpu & 24.23 & 27.63 & 30.77 & 31.58 & 28.55 & I & 49.23 & 47.00 & 58.34 & 51.52 \\
\hline & Average for the urban districts & 20.06 & 32.51 & 35.00 & 36.08 & 30.91 & & 48.14 & 50.48 & 61.86 & 53.49 \\
\hline \multirow[t]{5}{*}{ Outskirts } & Pudong & 7.41 & 32.48 & 36.11 & 37.30 & 28.33 & l & 59.15 & 63.28 & 85.76 & 69.40 \\
\hline & Jiading & 14.40 & 23.18 & 31.39 & 33.48 & 25.61 & l & 56.09 & 52.92 & 85.97 & 64.99 \\
\hline & Minhang & 11.69 & 30.65 & 33.29 & 34.03 & 27.42 & 1 & 53.80 & 63.05 & 91.88 & 69.58 \\
\hline & Baoshan & 16.42 & 32.36 & 33.64 & 40.14 & 30.64 & l & 69.49 & 69.12 & 102.42 & 80.34 \\
\hline & Average for the outskirts districts & 12.48 & 29.67 & 33.61 & 36.24 & 28.00 & & 59.63 & 62.09 & 91.51 & 71.08 \\
\hline \multirow[t]{7}{*}{ Suburbs } & Jinshan & 30.61 & 31.88 & 34.31 & 41.49 & 34.57 & l & 60.41 & 58.23 & 82.47 & 67.04 \\
\hline & Fengxian & 17.59 & 29.01 & 31.17 & 33.11 & 27.72 & l & 57.56 & 58.06 & 80.32 & 65.31 \\
\hline & Songjiang & 15.02 & 23.23 & 31.27 & 31.18 & 25.18 & l & 50.05 & 47.83 & 81.64 & 59.84 \\
\hline & Qingpu & 10.01 & 17.57 & 22.46 & 31.78 & 20.46 & l & 41.57 & 43.21 & 83.41 & 56.06 \\
\hline & Chongming & 29.26 & 35.04 & 40.25 & 42.98 & 36.88 & I & 65.46 & 64.97 & 77.44 & 69.29 \\
\hline & Average for the suburban districts & 20.50 & 27.35 & 31.89 & 36.11 & 28.96 & & 55.01 & 54.46 & 81.06 & 63.51 \\
\hline & Total & 15.50 & 30.23 & 33.74 & 37.98 & 29.36 & 1 & 54.63 & 56.62 & 76.53 & 62.59 \\
\hline
\end{tabular}

Note: /ndicates that these data could not be obtained from the data platform.

countries. For instance, in the UK, $90 \%$ of patients receive their initial diagnoses in the GP clinic, and $80 \%$ of chronic diseases are solved in community health centres. ${ }^{21}$ The possible reasons for this result is that, specifically, the program of signing with family doctors in Shanghai and other regions in China is voluntary for residents; in other words, there is no compulsory restriction by laws or medical insurance policies. However, in foreign countries, there are laws, medical insurance policies and other mandatory elements. For example, in Britain, all of the citizens over the age of 16 and foreigners who are on visas longer than six months must register with a GP so that residents can only go to a specialist hospital with the consent of their GP; otherwise, surgery and treatment costs will not be reimbursed, ${ }^{22}$ but acute patients can be directly sent to the hospital. ${ }^{23}$ Additionally, although the proportion of reimbursed consultations has increased in community health centres, there has been no particularly strong effect on medical care conduct. ${ }^{24}$ Similar to the UK, residents cannot go to specialized hospitals without permission. After specialist treatment, subsequent rehabilitation remains the responsibility of the GP; otherwise, it will not be reimbursed. Surgery and treatment costs can be reimbursed only if up-transfer requires surgery and is consented to by the GP.

Interestingly, in this study, we found that the utilization of schemes of signings with family doctors is higher in outskirts than in urban areas or the suburbs. Possible reasons for this effect is that the existing organization of medical resources is adequate in urban areas, and residents have been accustomed to seeing a doctor in secondary and tertiary hospitals, which leads to the proportions of the key population and seniors aged 65 years and above who have signed contracts being lower in urban areas. ${ }^{25,26}$ This result indicated that, for those regions with abundant medical service from large hospitals, there should be more incentive measures for promoting the programs.

\section{Limitations}

First, the schemes of signings with family doctors have not been conducted for a long period of time, and its 
effectiveness evaluation (including quality indicators such as satisfaction, disease incidence and health costs in the region) should be further measured and included in the analysis. Second, the study was conducted only in Shanghai, and data from other regions were difficult to collect. Further comparisons between different regions of China are required in the future.

\section{Conclusion}

The practice of facilitate signing with family doctors in Shanghai has accumulated considerable evidence. However, the evaluation showed that the number of family doctors was relatively low, as well as the fact that the team still requires more experienced gynaecology and paediatric professionals, compared with those in Western countries. In Shanghai, the innovative solutions for promoting and supervising the schemes of signings with family doctors can provide experiences for other regions or countries. However, the relatively low proportion of the permanent resident population who signed a contract, the proportion of individuals seeking medical services in community health centres, the proportion of individuals seeking medical services from multiple medical institutions and the proportions of individuals who signed contracts based on various indicators in urban areas suggest that the contract system for family doctors should be further improved in these aspects.

\section{Abbreviations}

GPs, general practitioners.

\section{Ethical Approval and Consent}

Ethical consideration was approved by the Ethics Committee of Fudan University (IRB00002408\&FWA00002399). Participants gave informed consent prior to data collection. This study was conducted in accordance with the Declaration of Helsinki, the Belmont Report, CIOMS Guideline, and International Conference on Harmonization in Good Clinical Practice (ICH-GCP).

\section{Acknowledgments}

We sincerely acknowledge and appreciate the assistance of the Shanghai Family Doctor Signing Data Platform for their help in providing the data.

\section{Funding}

The design of the experiment was supported by the Special Clinical Research on Health Industry of Shanghai
Municipal Health Commission (201940435, 20204Y0476). Data extraction was funded by Pudong New Area Health System Advantages of General Medicine Discipline (PWYq2020-02). The analysis and interpretation of the data were funded by the Shanghai Jiao Tong University 2021 Annual Hospital Management Construction Project of China Hospital Development Institute (CHDI-2021-B-36) and the Shanghai Health System Excellent Young Talents Project (2018YQ52). The writing and revision, including the language improvement, were sponsored by the Excellent Academic Leader of Public Health in Shanghai (GWV-10.2-XD07) and Philosophy and Social Science Research Major Projects of the Ministry of Education (20JZD027).

\section{Disclosure}

The authors report no conflicts of interest in this work.

\section{References}

1. WHO. Declaration of Alma-Ata International Conference on Primary Health Care 1978. Available from: https://www.who.int/publications/ almaata_declaration_en.pdf. Accessed July 8, 2021.

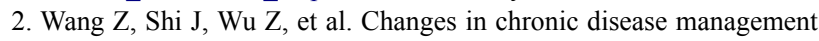
among community health centers (CHCs) in China: has health reform improved CHC ability? Int J Health Plann Manage. 2017;32 (3):317-328. doi:10.1002/hpm.2433

3. Chen Z. Launch of the health-care reform plan in China. Lancet. 2009;373(9672):1322-1324. doi:10.1016/s0140-6736(09)60753-4

4. Hung LM, Rane S, Tsai J, Shi LY. Advancing primary care to promote equitable health: implications for China. Int $J$ Equity Health. 2012;11:2. doi:10.1186/1475-9276-11-2

5. Council S. Guidelines of the state council on the establishment of a system of general practitioners. Available from: http://www.gov.cn/ zhengce/content/2011-07/06/content_123.htm. Accessed July 8, 2021.

6. China TCPsGotPsRo. Guiding opinions on establishing a general practitioner system 2011. Available from: http://www.gov.cn/ zhengce/content/2011-07/06/content_6123.htm. Accessed July 8, 2021.

7. China TCPsGotPsRo. Decision of the CCCPC on some major issue concerning comprehensively deepening the reform 2013. Available from: http://www.gov.cn/jrzg/2013-11/15/content_2528179.htm. Accessed July 10, 2021.

8. China TCPsGotPsRo. Guiding opinions on promoting the construction of a hierarchical medical system 2015. Available from: http:// www.gov.cn/xinwen/2015-09/11/content_2929789.htm. Accessed July $11,2021$.

9. China TCPsGotPsRo. Guiding opinions on regulating the management of family doctor contract service 2018. Available from: http:// www.gov.cn/zhengce/zhengceku/2018-12/31/content_5435461.htm. Accessed July 12, 2021.

10. Wu Q. Shanghai: lightening the spark of the urban health. China Health. 2021;5:44-45.

11. Municipality HCoS. Guiding opinions on the comprehensive promotion of the family doctor system in Shanghai 2013. Available from: http://wsjkw.sh.gov.cn/ygwj/20180525/0012-23700.html. Accessed July 18, 2021. 
12. Municipality HCoS. Notice on further fulfilling the Family Doctor Contract Service Program in Shanghai 2017. Available from: http:/ wsjkw.sh.gov.cn/jcws2/20180815/0012-57731.html. Accessed July 8, 2021

13. Feng S, Cheng A, Luo Z, Xiao Y, Zhang L. Effect of family doctor contract services on patient perceived quality of primary care in southern China. BMC Fam Pract. 2020;21(1):218. doi:10.1186/ s12875-020-01287-7

14. Xia YH, Hong ZH, Cao R, Liu GH, Cai H, He Q. Information construction in community health service centers and implications for policy. Chinese J General Pract. 2019;22(25):3068-3075.

15. Rublee DA. The quality of care: how can it be assessed? JAMA. 1989;261(8):1151. doi:10.1001/jama.1989.03420080065026

16. Shang XP, Huang YM, Li BE, et al. Residents' awareness of family doctor contract services, status of contract with a family doctor, and contract service needs in Zhejiang Province, China: a cross-sectional study. Int $J$ Environ Res Public Health. 2019;16(18):3312. doi:10.3390/ijerph16183312

17. Sun X, Jing L, Li M, Zhang QF, Lu GR, Bai J. The reform of "capitation payment" of the new rural cooperative medical insurance in Pudong new area of Shanghai and its effects. Chin J General Pract. 2014;13(10):801-803.

18. Shanghai Municipal Health Commission. Shanghai health statistics in 2020. Available from: http://wsjkw.sh.gov.cn/tjsj2/20210426/ eb18f046dea54e129bd3acb3dfbc95cc.html. Accessed July 8, 2021.

19. Van den Bussche H. The future problems of general practice in Germany: current trends and necessary measures. Bundesgesundheitsblatt Gesundheitsforschung Gesundheitsschutz. 2019;62(9):1129-1137. doi:10.1007/s00103-019-02997-9
20. Zhang XJ, Zhu K. Review of remuneration of general practitioners in some developed countries. Chin J General Pract. 2014;17(17):1931$33+36$.

21. Liu YJ, Liu N, Zhang Q, Wang Z, Gu YL, Li ZY. Financial incentive policies for general practitioners in the UK and its inspiration for China. Chin J General Pract. 2018;21(25):3033-37+43.

22. Coskeran T, Denman A, Phillips P, Tornberg R. A cost-effectiveness analysis of domestic radon remediation in four primary care trusts located in Northamptonshire, UK. Health Pol. 2005;71(1):43-56. doi:10.1016/j.healthpol.2004.05.003

23. National Clinical Guideline Centre. National Institute for Health and Clinical Excellence: Guidance. Patient Experience in Adult NHS Services: Improving the Experience of Care for People Using Adult NHS Services: Patient Experience in Generic Terms. London: Royal College of Physicians (UK) Copyright; 2012.

24. Wang HH, Wang JJ, Zhou ZH, Wang XW, Xu L. General practice education and training in southern China: recent development and ongoing challenges under the health care reform. Malaysian Fam Phys. 2013;8(3):2-10.

25. Yang Y, Chen N, Cheng MW, et al. Perceptions among medical staff in community health centres of coping capacity regarding infectious disease epidemics: a cross-sectional study in Shanghai, China. Int J Gen Med. 2021;14:1251-1261. doi:10.2147/IJGM.S295310

26. Shi JW, Jin H, Shi LY, et al. The quality of primary care in community health centers: comparison among urban, suburban and rural users in Shanghai, China. BMC Fam Pract. 2020;21(1):178. doi:10.1186/s12875-020-01250-6
International Journal of General Medicine

\section{Publish your work in this journal}

The International Journal of General Medicine is an international, peer-reviewed open-access journal that focuses on general and internal medicine, pathogenesis, epidemiology, diagnosis, monitoring and treatment protocols. The journal is characterized by the rapid reporting of reviews, original research and clinical studies

\section{Dovepress}

across all disease areas. The manuscript management system is completely online and includes a very quick and fair peer-review system, which is all easy to use. Visit http://www.dovepress.com/ testimonials.php to read real quotes from published authors. 